This item was submitted to Loughborough's Research Repository by the author.

Items in Figshare are protected by copyright, with all rights reserved, unless otherwise indicated.

\title{
Dynamics and efficiency of planetary gear sets for hybrid powertrains
}

PLEASE CITE THE PUBLISHED VERSION

http://dx.doi.org/10.1177/0954406215590644

PUBLISHER

SAGE @ IMechE

VERSION

AM (Accepted Manuscript)

PUBLISHER STATEMENT

This work is made available according to the conditions of the Creative Commons Attribution-NonCommercialNoDerivatives 4.0 International (CC BY-NC-ND 4.0) licence. Full details of this licence are available at: https://creativecommons.org/licenses/by-nc-nd/4.0/

\section{LICENCE}

CC BY-NC-ND 4.0

\section{REPOSITORY RECORD}

Mohammadpour, Mahdi, Stephanos Theodossiades, and Homer Rahnejat. 2019. "Dynamics and Efficiency of Planetary Gear Sets for Hybrid Powertrains". figshare. https://hdl.handle.net/2134/18011. 


\title{
Dynamics and Efficiency of Planetary Gear Sets for Hybrid Power trains
}

\author{
M. Mohammadpour, S. Theodossiades and H. Rahnejat \\ Wolfson School of Mechanical \& Manufacturing Engineering, Loughborough University, \\ Loughborough, UK
}

\begin{abstract}
The paper presents a tribo-dynamic model for planetary gear sets of Hybrid-Electric-Vehicle (HEV) configurations. The model comprises a 6 degree-of-freedom torsional multi-body dynamic system, as well as a tribological contact model in order to evaluate the lubricant film thickness, friction and efficiency of the meshing gear teeth contacts. The tribological model takes into account the non-Newtonian, thermal-mixed elastohydrodynamic regime of lubrication. Analysis is performed for a HEV C-segment vehicle. The simulated conditions correspond to cases of power supplied by either the engine or the electric motor. The results illustrate that in the electric motor drive mode, improved Noise, Vibration and Harshness $(\mathrm{NVH})$ refinement would be expected, whereas better transmission efficiency is achieved in the internal combustion engine drive mode.
\end{abstract}

Keywords: planetary gear set, hybrid power trains, dynamics, lubrication, transmission efficiency

\section{Nomenclature}

$\begin{array}{cl}A & \text { Apparent contact area } \\ A_{a} & \text { Asperity contact area } \\ A_{f} & \text { Vehicle frontal area } \\ B & \text { Backlash } \\ b & \text { Half-width of Hertzian contact } \\ C_{D} & \text { Drag coefficient } \\ c & \text { Damping coefficient } \\ c^{\prime} & \text { Thermal capacity of conjunctional solids } \\ E & \text { Young's modulus of elasticity } \\ E^{\prime} & \text { Equivalent (reduced) modulus of elasticity } \\ F_{f l a n k} & \text { Flank load } \\ f & \text { Contact friction } \\ f_{v} & \text { Viscous friction } \\ f_{b o} & \text { Boundary friction } \\ f_{r l} & \text { Rolling friction coefficient of tyre-road interactions } \\ g_{\alpha} & \text { Length of path of contact } \\ h_{c 0} & \text { Central contact lubricant film thickness } \\ I & \text { Mass moment of inertia } \\ \dot{K} & \text { Lubricant conductivity } \\ K^{\prime} & \text { Surface solid conductivity } \\ k & \text { Stiffness } \\ L & \text { Gear flank width }\end{array}$


$R \quad$ Resisting force

$r \quad$ Gear teeth contact radii

$P L \quad$ Power loss

$P_{e} \quad$ Base pitch

$\bar{p} \quad$ Average contact pressure $(\mathrm{Pa})$

$T$ Torque

$V \quad$ Speed of entraining motion of lubricant

$V_{v} \quad$ Vehicle speed

$\Delta V \quad$ Sliding velocity

$W \quad$ Vehicle weight

$W_{a} \quad$ Load carried by asperities

$X \quad$ Instantaneous meshing position

$Z \quad$ Number of teeth

\section{Greek symbols}

$\alpha \quad$ Pressure-viscosity coefficient

$\varepsilon \quad$ Pressure-induced shear coefficient of bounding surfaces

$\eta_{0} \quad$ Atmospheric dynamic viscosity of Lubricant

$\theta$ Torsional degrees of freedom

$\lambda \quad$ Stribeck's oil film parameter

$\rho^{\prime} \quad$ Density of conjunctional solids' material

$\sigma \quad$ Composite surface roughness of contacting solids

$\tau_{L} \quad$ Lubricant's limiting shear stress

$\tau_{0} \quad$ Lubricant's limiting shear stress at atmospheric pressure

$v \quad$ Poisson's ratio

$\varphi$ Pressure angle

\section{Subscripts}

$\begin{array}{cl}\text { ar } & \text { Aerodynamic } \\ b & \text { Gears' base circle } \\ b o & \text { Boundary regime of lubrication } \\ c & \text { Carrier } \\ \text { dif } & \text { Differential } \\ p & \text { Planet gear } \\ p l a n & \text { Planetary gear set } \\ r & \text { Ring gear } \\ r e d & \text { Reducer } \\ r l & \text { Rolling } \\ r p & \text { Ring to planet } \\ s & \text { Sun gear } \\ s p & \text { Sun to planet } \\ T & \text { Total } \\ t & \text { Tyre } \\ v & \text { Viscous } \\ w & \text { Wheel }\end{array}$

\section{Abbreviations}

DTE Dynamic Transmission Error 
HEV Hybrid-Electric-Vehicle

NVH Noise, Vibration and Harshness

\section{Introduction}

Planetary or epicyclic gear sets are used in many applications, from wind turbines to automotive drive trains. They are extensively employed in the automotive sector [1-6]. There has recently been growing use of planetary gear sets in automotive applications for hybrid vehicles. This is because of their good transmission efficiency. Various reported works show the superior transmission efficiency of planetary gears, as well as their compactness compared with the more traditional drive trains. Epicyclic gears are also able to deliver a wider range of transmission ratios and are generally regarded to be quieter [7]. Thus, from design perspective it is important to develop analyses tools which combine the study of system dynamics and tribological efficiency of epicyclic gears, as well as their supporting bearings of their retaining shafts $[8,9]$. This multi-physics, multi-scale approach is often referred to as tribo-dynamics.

A key element of the interactions between the overall system inertial dynamics at the macroscale with the gear teeth meshing and bearing contacts at the micro-scale is the generated friction. Friction acts as an energy sink mechanism that may attenuate, and eventually reduce the excessive supplied energy, thus contributing to NVH refinement, particularly in the progressively lighter and compact power trains [10 - 13]. At the same time, it is shown that the frictional power loss also affects the transmission efficiency [8, 14-15]. Thus, an "optimal” balance should be struck between energy efficiency and NVH refinement. There is yet a third link between system dynamics (NVH) and contact mechanics (tribology). This is with regard to the rigidity (stiffness) and damping of the fluid film in the lubricated conjunctions, which alters according to the prevailing regime of lubrication, which itself is dependent on the driving conditions.

This paper presents a torsional multi-body dynamics model of a planetary gear set, coupled with a tribological model of their gear teeth lubricated conjunctions to investigate NVH and transmission efficiency in a simultaneous manner. This is a novel approach, which has not hitherto been reported in literature. The model is able to provide predictions under various operating conditions, particularly where optimisation of contradictory requirements are sought, such as improved fuel efficiency and NVH refinement.

The power train of a HEV C-segment vehicle is analysed. The simulated conditions correspond to cases of power supplied by either the engine or the electric motor (not their combination). The results illustrate that in the electric motor drive mode, more refined $\mathrm{NVH}$ would be expected, whereas better transmission efficiency is expected in the internal combustion engine drive mode.

\section{Hybrid system configuration}

A hybrid power train, comprising an Electric Motor (EM) and an Internal Combustion (IC) engine is considered (Figure 1). A planetary gear set is used as a power split system between 
these two sources of propulsion. A reduction gear set is employed between the output of the planetary (p) gear set and the differential unit. The IC engine is connected to the carrier (c). The EM output is connected to the sun gear (s) and the total output power always flows through the ring (r) gear to the reducer gear set. The latter provides the output power to the differential. Based on the control protocol of the system, the input power can be supplied from the IC engine, EM or their combination.

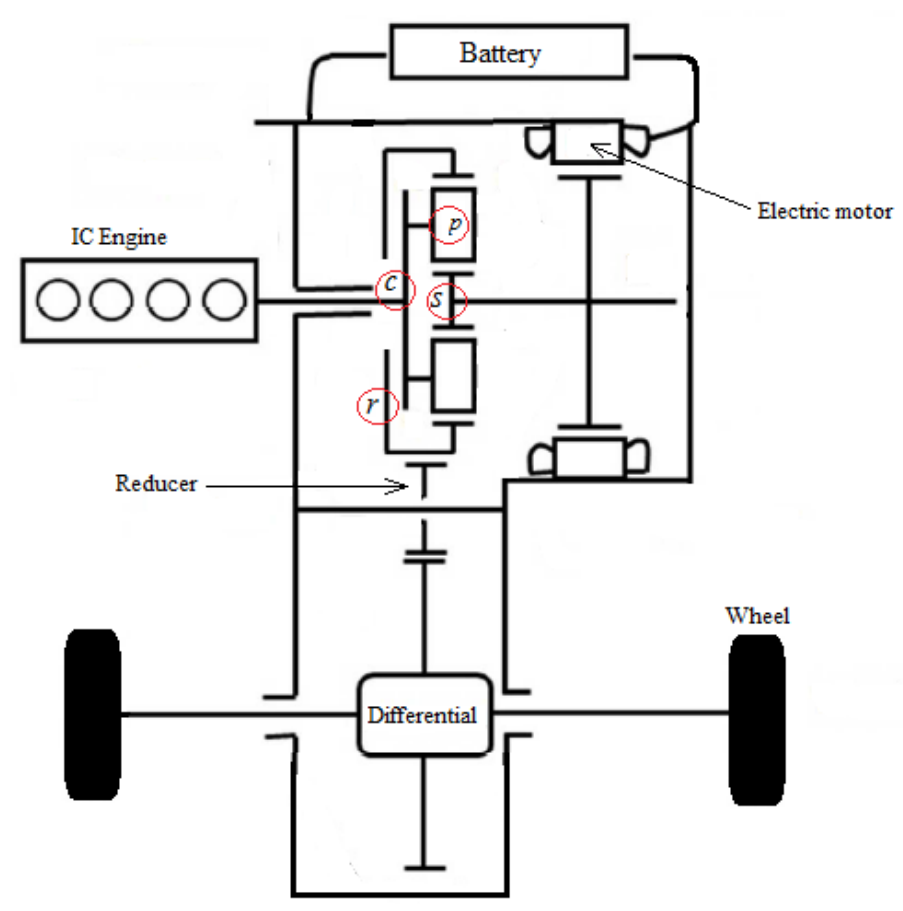

Figure 1: The hybrid powertrain configuration

\section{The dynamics model}

The dynamics model of the planetary gear set comprises 6 torsional degrees of Freedom, corresponding to the sun gear, the ring gear, the carrier and the three planets. In the current analysis the lateral motions of the gears' supporting shafts and any time-varying effects of the teeth meshing stiffness are not taken into account [16]. Nevertheless, the methodology can be extended to include these more complex system behaviour and non-linear effects. The schematics of the system, showing the connections between the ring gear, carrier, planets and the sun gear are shown in figure 2 . 


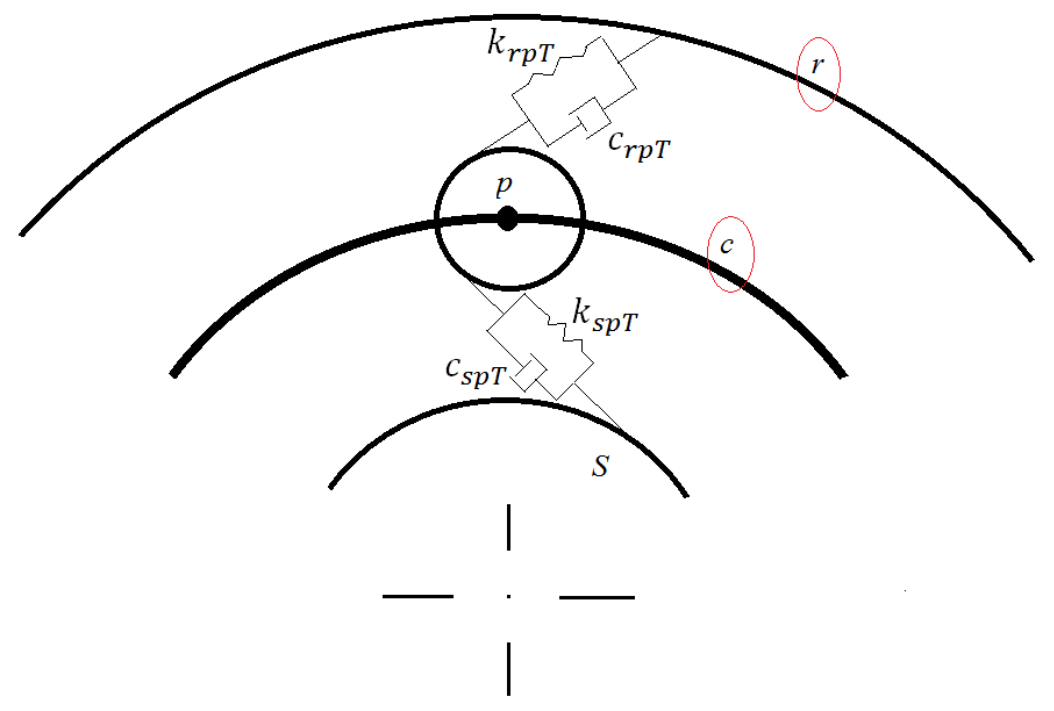

Figure 2: Schematics of the gear set.

The system's equations of motion are obtained as:

$$
\left\{\begin{array}{l}
I_{s} \ddot{\theta}_{s}+\cos \varphi r_{s} \sum_{i=1}^{3}\left(D T E_{s p i} k_{s p i T}+D \dot{T} E_{s p i} c_{s p i T}\right)=T_{s} \\
I_{r} \ddot{\theta}_{r}+\cos \varphi r_{r} \sum_{i=1}^{3}\left(D T E_{r p i} k_{r p i T}+D \dot{T} E_{r p i} c_{r p i T}\right)=T_{r} \\
I_{c} \ddot{\theta}_{c}+\cos \varphi r_{c} \sum_{i=1}^{3}\left(D T E_{s p i} k_{s p i T}+D \dot{T} E_{s p i} c_{s p i T}+D T E_{r p i} k_{r p i T}+D \dot{T} E_{r p i} c_{r p i T}\right)=T_{c} \\
I_{p 1} \ddot{\theta}_{p 1}+\cos \varphi r_{p}\left(D T E_{s p 1} k_{s p 1 T}+D \dot{T} E_{s p 1} c_{s p 1 T}-D T E_{r p 1} k_{r p 1 T}-D \dot{T} E_{r p 1} c_{r p 1 T}\right)=0 \\
I_{p 2} \ddot{\theta}_{p 2}+\cos \varphi r_{p}\left(D T E_{s p 2} k_{s p 2 T}+D \dot{T} E_{s p 2} c_{s p 2 T}-D T E_{r p 2} k_{r p 2 T}-D \dot{T} E_{r p 2} c_{r p 2 T}\right)=0 \\
I_{p 3} \ddot{\theta}_{p 3}+\cos \varphi r_{p}\left(D T E_{s p 3} k_{s p 3 T}+D \dot{T} E_{s p 3} c_{s p 3 T}-D T E_{r p 3} k_{r p 3 T}-D \dot{T} E_{r p 3} c_{r p 3 T}\right)=0
\end{array}\right.
$$

where, $i=1 \rightarrow 3$ represents the number of planet gear braches.

The Dynamic Transmission Error (DTE) is in fact the mutual approach or separation of two engaged teeth along their path of contact. This is an important dynamic response parameter, used to predict the $\mathrm{NVH}$ behaviour of gearing systems. It is calculated for the different meshing contacts as:

$D T E_{s p i}=f a\left(\theta_{s} r_{s}-\theta_{p i} r_{p}-\theta_{c} r_{c}\right)$

$D \dot{T} E_{s p i}=f a\left(\dot{\theta}_{s} r_{s}-\dot{\theta}_{p i} r_{p}-\dot{\theta}_{c} r_{c}\right)$

$D T E_{r p i}=f a\left(\theta_{p i} r_{p}-\theta_{r} r_{r}-\theta_{c} r_{c}\right)$

$D \dot{T} E_{r p i}=f a\left(\dot{\theta}_{p i} r_{p}-\dot{\theta}_{r} r_{r}-\dot{\theta}_{c} r_{c}\right)$

When a given gearing component is assumed as stationary, the corresponding equations of motion in equation set (1) are constrained and the relevant terms in equations (2)-(5) are ignored. 
The teeth backlash introduces a system non-linearity, leading to teeth-pair separation and vibration response (jump phenomenon) in the vicinity of system resonances. The effect of the backlash is taken into account using the following piecewise linear relationships:

$$
\left\{\begin{array}{rr}
f a=1 & 0<D T E \text { or DTE }<-B \\
f a=0 & -B<D T E<0
\end{array}\right.
$$

The gear pairs used for this analysis are spur gears with the meshing stiffness for all the teeth pairs in contact considered to be linear. As the contact ratio exceeds unity, at any instance 1 or 2 teeth pairs remain in simultaneous contact. This is shown in figure 3. A piecewise linear step function is considered to account for the total effective meshing stiffness $\left(k_{T}\right)$ variation as a combination of the individual gear teeth pair meshing stiffness values $(k)$ :

$\left\{\begin{array}{lr}k_{T}=2 k & p_{e}<X \text { or } X<g_{\alpha}-p_{e} \\ k_{T}=k & g_{\alpha}-p_{e}<X<p_{e}\end{array}\right.$

The phase difference between different meshing points can play an important role. For instance, Ambarisha and Parker [17] investigated the possibility of suppressing the planet modal response through mesh phasing. In the present work the emphasis has been primarily placed on the examination of the effect of different driving power modes, thus it is assumed that there is no phase difference at different meshing points between the gear sets.

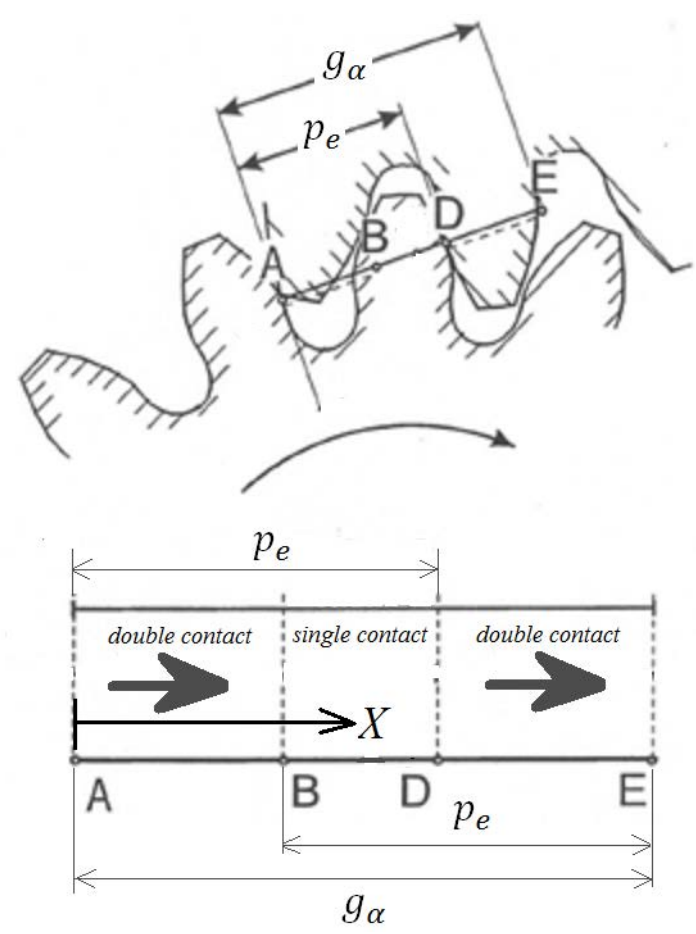

Figure 3: Meshing cycle of a spur gear pair 
During meshing, hysteretic material damping needs to be included [12]. The damping coefficient for the contact of a single meshing teeth pair can be obtained using:

$c=\frac{0.009 k}{f_{m}}$

where, $f_{m}$ is the meshing frequency. In order to obtain the total damping variation during meshing, a similar approach to equation (8) is employed.

\section{The tribological model}

Gears under high loads typically operate in mixed regime of lubrication. The friction in the mixed regime of lubrication comprises two contributions; viscous shear of the thin lubricant film and direct interaction of ubiquitous asperities on the boundary solid surfaces. Therefore, the total friction becomes:

$$
f=f_{v}+f_{b o}
$$

To determine boundary friction, the Greenwood and Tripp [18] method is used. The method assumes a Gaussian distribution of asperities on the solid meshing teeth surfaces. A proportion of load is carried by these asperities on the opposing contacting surfaces, when mixed or boundary regimes of lubrication are encountered. This is predicted, based on the

Stribeck's oil film parameter: $\lambda=\frac{h_{c 0}}{\sigma} \leq 3$, where $\sigma$ is the root mean square composite surface roughness of the counterfaces. Usually, a very small proportion of load is carried by the asperities protruding through an insufficiently thick lubricant film. The share of contact load carried by the asperities is given by [18]:

$W_{a}=\frac{16 \sqrt{2}}{15} \pi(\xi \beta \sigma)^{2} \sqrt{\frac{\sigma}{\beta}} E^{\prime} A F_{5 / 2}(\lambda)$

where, the statistical function $F_{5 / 2}(\lambda)$ for the Gaussian distribution of asperities becomes [19]:

$$
F_{5 / 2}(\lambda)=\left\{\begin{array}{rr}
-0.004 \lambda^{5}+0.057 \lambda^{4}-0.296 \lambda^{3}+0.784 \lambda^{2}-1.078 \lambda+0.617 ; & \text { for } \lambda \leq 3 \\
0 & ; \text { for } \lambda>3
\end{array}\right.
$$


Usually the roughness parameter $(\xi \beta \sigma)$ is in the range $0.03-0.07$ for steel surfaces. The ratio $\sigma / \beta$ is a representation of the average asperity slope [19], which is in the range $10^{-4}-10^{-2}$ [19]. In the current study it is assumed that $\xi \beta \sigma=0.055$ and $\sigma / \beta=10^{-3}$.

The asperity contact area is obtained as [18]:

$A_{a}=\pi^{2}(\xi \beta \sigma)^{2} A F_{2}(\lambda)$

The statistical function $F_{2}(\lambda)$ employed in the equation above is expressed as follows [19]:

$F_{2}(\lambda)=\left\{\begin{array}{rr}-0.002 \lambda^{5}+0.028 \lambda^{4}-0.173 \lambda^{3}+0.526 \lambda^{2}-0.804 \lambda+0.500 ; & \text { for } \lambda \leq 3 \\ 0 \quad & \text { for } \lambda>3\end{array}\right.$

There is a thin layer of adsorbed film at the summit of asperities or entrapped in their contact, which is subjected to non-Newtonian shear, thus [20]:

$f_{b o}=\tau_{L} A_{a}$

where, $\tau_{L}$ is the lubricant's limiting shear stress [20-21]:

$\tau_{L}=\tau_{0}+\varepsilon P_{m}$

where, $P_{m}=\frac{W_{a}}{A_{a}}$.

Thin elastohydrodynamic films in the meshing teeth pairs of gears at high loads are often subjected to non-Newtonian shear behaviour. Evans and Johnson [22] reported an analyticalexperimental expression for viscous friction under these conditions. This also takes into account the effect of heat generated in the contact:

$f_{v}=F_{\text {flank }}\left(0.87 \alpha \tau_{0}+1.74 \frac{\tau_{0}}{\bar{p}} \ln \left(\frac{1.2}{\tau_{0} h_{c 0}}\left(\frac{2 \dot{K} \eta_{0}}{1+9.6 \zeta}\right)^{1 / 2}\right)\right)$

where:

$\zeta=\frac{4}{\pi} \frac{\dot{K}}{h_{c 0} / R(X)}\left(\frac{\bar{p}}{E^{\prime} R(X) K^{\prime} \rho^{\prime} c^{\prime} V}\right)^{1 / 2}$

The frictional power loss becomes: 
$P L=f \Delta V(X)$

$X$ is the position of a meshing teeth pair along the path of contact, measured from the beginning of meshing (figure 3). The lubricant film thickness is obtained as [23]:

$h_{c 0}=2.5 R(X)\left(\frac{V(X) \eta_{0} \alpha}{R(X)}\right)^{0.7}\left(\alpha E^{\prime}\right)^{0.1}\left(\frac{F_{\text {flank }} \alpha}{2 L b}\right)^{-0.26}$

where, the required data for the viscous friction and calculation of film thickness are:

$E^{\prime}=\frac{1}{\left(\frac{1-v_{1}^{2}}{E_{1}}+\frac{1-v_{2}^{2}}{E_{2}}\right)}$

$b=\left(\frac{8 F_{f l a n k} R(X)}{L \pi E^{\prime}}\right)^{1 / 2}$

$F_{\text {flank }}=D T E * k_{T}+D \dot{T} E * c_{T}$

$R(X)=\frac{\left(r_{b 1} \operatorname{tg}(\varphi)+X\right)\left(r_{b 2} \operatorname{tg}(\varphi)-X\right)}{\left(r_{b 1}+r_{b 2}\right) \operatorname{tg}(\varphi)}$

$V(X)=\dot{\theta} r_{1} X \cos (\varphi)\left(\frac{1}{r_{b 1}}-\frac{1}{r_{b 2}}\right)+2 \sin (\varphi)$

$\Delta V(X)=\dot{\theta} r_{1} X \cos (\varphi)\left(\frac{1}{r_{b 1}}-\frac{1}{r_{b 2}}\right)$

\section{Applied torque on the gear set}

The applied torque on the output of the gear set (ring gear) takes into account the vehicle's longitudinal dynamics, including rolling resistance $\left(R_{r l}\right)$, aerodynamic resisting force $\left(R_{a r}\right)$ and any gradient loading $\left(R_{G}\right)[15]$ :

$T_{w}=r_{t} \sum F=r_{t}\left(R_{a r}+R_{r l}+R_{G}\right)$

where, $r_{t}$ is the laden dynamic tyre radius and

$R_{a r}=\frac{\rho}{2} C_{D} A_{f} V_{v}^{2}, \quad R_{r l}=f_{r l} W$

$f_{r l}$ is the coefficient of rolling resistance and $W$ is the vehicle weight. $R_{G}$ is ignored for vehicle motion on a flat road (zero gradient). 
The instantaneous resisting torque (resident on the ring gear) is defined as:

$T_{r}=\frac{T_{w}}{R_{\text {red }} R_{\text {dif }}}+T_{f r}$

where $T_{f r}$ is the friction torque. This is obtained using the definition of power loss as:

$T_{f r}=\frac{P L_{T}}{\dot{\theta}_{r}}$

The input torque can be supplied by the IC engine, EM or both. In this study only one power source is assumed to act at any instant of time and the input/resistance excitation torque terms remain in equilibrium. In fact, it is assumed that at any vehicle speed, sufficient torque is supplied to maintain steady state conditions. Therefore, the input torque can be stated as:

$T_{s}$ or $T_{C}=\frac{T_{r}}{R_{\text {plan }}}$

The calculated resisting torque from equation (28) and the driving torques from equation (30) are directly supplied to the equation set (1) as the excitation source.

where $R_{\text {plan }}$ is the transfer ratio of the planetary gear set which changes according to different configurations. The relationship between the velocities of different components of the planetary gear set can be expressed as:

$\left(Z_{r}+Z_{s}\right) \dot{\theta}_{c}=\dot{\theta}_{r} Z_{r}+\dot{\theta}_{s} Z_{s}$

When a gearing component is stationary, then its velocity is set to zero. Therefore, in order to maintain steady state conditions, the required torque resident on the input shaft is obtained from equation (30) with the transfer ratio obtained using equation (31).

\section{Results and discussion:}

Tribo-dynamics of a C-segment class hybrid electric vehicle (HEV) equipped with an 1.61 gasoline IC engine and a maximum power of $80 \mathrm{~kW}$ at 5,000 rpm is studied. The maximum torque is $140 \mathrm{Nm}$. The electric motor is a permanent magnet synchronous machine. It has a maximum power of $40 \mathrm{~kW}$ and a top speed of 10,200 rpm and a maximum torque of $75 \mathrm{Nm}$. 
Tables 1-3 list the gear set data, mechanical properties and lubricant rheological data, as well as the pertinent vehicle data used in [24].

Table 1: Gear set data

\begin{tabular}{|c|c|}
\hline Sun radius, $r_{s}$ & $0.024[\mathrm{~m}]$ \\
\hline Planet radius, $r_{p}$ & $0.016[\mathrm{~m}]$ \\
\hline Ring radius, $r_{r}$ & $0.056[\mathrm{~m}]$ \\
\hline Pressure angle & $21.34\left[^{\circ}\right]$ \\
\hline Helix angle & $0\left[^{\circ}\right]$ \\
\hline Sun number of teeth, $Z_{s}$ & $30[---]$ \\
\hline Planet number of teeth, $Z_{p}$ & $20[---]$ \\
\hline Ring number of teeth, $Z_{r}$ & $70[---]$ \\
\hline Number of planet branches & 3 \\
\hline Sun-planet stiffness, $k_{s p}$ & $2 \times 10^{8}[\mathrm{~N} / \mathrm{m}]$ \\
\hline Ring-planet stiffness, $k_{r p}$ & $2 \times 10^{8}[\mathrm{~N} / \mathrm{m}]$ \\
\hline Sun moment of inertia, $I_{s} / r_{s}^{2}$ & $0.136[\mathrm{~kg}]$ \\
\hline Planet moment of inertia, $I_{p} / r_{p}^{2}$ & $0.05[\mathrm{~kg}]$ \\
\hline Ring moment of inertia, $I_{r} / r_{r}^{2}$ & $0.389[\mathrm{~kg}]$ \\
\hline Carrier moment of inertia, $I_{c} / r_{c}^{2}$ & $0.75[\mathrm{~kg}]$ \\
\hline
\end{tabular}

Table 2: Lubricant and material data

\begin{tabular}{|c|c|}
\hline Pressure viscosity coefficient & $2.1 \times 10^{-8}\left[\mathrm{~Pa}^{-1}\right]$ \\
\hline Atmospheric dynamic viscosity & $0.08[\mathrm{~Pa} . \mathrm{s}]$ \\
\hline Lubricant Eyring shear stress & $2.3[\mathrm{MPa}]$ \\
\hline Heat capacity of the fluid & $0.14\left[\mathrm{~J} / \mathrm{kg}^{\circ} \mathrm{K}\right]$ \\
\hline Thermal conductivity of the fluid & $2000\left[\mathrm{~W} / \mathrm{m}^{\circ} \mathrm{K}\right]$ \\
\hline Modulus of elasticity of the contacting solids & $200[\mathrm{GPa}]$ \\
\hline Poisson's ratio of the contacting solids & $0.3[---]$ \\
\hline Density of the contacting solids & $7850\left[\mathrm{~kg} / \mathrm{m}^{3}\right]$ \\
\hline Thermal conductivity of the contacting solids & $46\left[\mathrm{~W} / \mathrm{m}^{\circ} \mathrm{K}\right]$ \\
\hline Heat capacity of the contacting solids & $470\left[\mathrm{~J} / \mathrm{kg}^{\circ} \mathrm{K}\right]$ \\
\hline Surface roughness of solids, Ra & $0.6[\mu \mathrm{m}]$ \\
\hline Pressure-induced shear coefficient $(\varepsilon)$ & $0.047[---]$ \\
\hline
\end{tabular}


Table 3: Vehicle data

\begin{tabular}{|c|c|}
\hline Frontal area & $2.2\left[\mathrm{~m}^{2}\right]$ \\
\hline Coefficient of rolling resistance & $0.0166[---]$ \\
\hline Drag coefficient & $0.33[---]$ \\
\hline Air density & $1.22\left[\mathrm{~kg} / \mathrm{m}^{3}\right]$ \\
\hline Vehicle weight & $1300[\mathrm{~kg}]$ \\
\hline Tyre (type) & $\mathrm{P} 195 / 50 \mathrm{R} 16$ \\
\hline Tyre loaded radius & $0.2388[\mathrm{~m}]$ \\
\hline
\end{tabular}

Since the aim of the analysis is to study the NVH and tribological performance of the planetary gear set, a vehicle speed sweeps simulation are performed from $15 \mathrm{~km} / \mathrm{h}$ to 100 $\mathrm{km} / \mathrm{h}$, one in the EM power mode and the other with the IC engine power alone. This approach enables direct comparison of the planetary gear set performance under different driving power modes regardless of the HEV control strategy at any particular speed.

As the main contributory source to NVH refinement, the DTE is monitored (as represented by equations (2-5)), also shown in figure 4. Here the DTE of one of the sun-planet meshing points is depicted. Therefore, equation (2) is used in this instance. The extent of DTE fluctuations provides a measure of the teeth contact pressure perturbations, which are expected to result in system vibration and noise radiation. Therefore, the DTE can be considered as a measure of both air-borne and structure-borne noise contributions. The higher peak-to-peak oscillations translate to worsening $\mathrm{NVH}$ conditions. Another piece of information extracted from the DTE results is the ensuing teeth pair separation and any subsequent impacts [13, 25]. As demonstrated by equation (6), DTE $=0$ is the threshold of this behaviour. On occasions, severe vibrations occur with meshing teeth pairs exhibiting doublesided impacts (at the coasting, as well as the driving face of the meshing teeth). This occurs when $D T E<-B$. Figure 4 shows the maximum and minimum DTE peak values during the vehicle speed sweep. It shows that during EM drive mode the peak-to-peak oscillatory amplitude is generally smaller than during the IC engine drive mode, which corresponds to better NVH refinement. At around $60 \mathrm{~km} / \mathrm{h}$ speed resonance occurs, leading to double-sided gear teeth impacts. One should also note that due to system nonlinear resonance jump phenomenon at this speed, a smooth bend in amplitude is expected. This represents the worse possible conditions in terms of $\mathrm{NVH}$ performance. In gearing systems the excitation source is usually at the meshing frequency. As the result of different system configuration during the various power modes, the meshing frequency (excitation frequency) varies. Figure 4 also shows that when in EM drive mode, teeth pair separation occurs for a shorter velocity range when compared with the IC engine drive mode. This phenomenon takes place in a higher speed range when in the IC engine power mode, resulting in single-sided teeth impacts. 


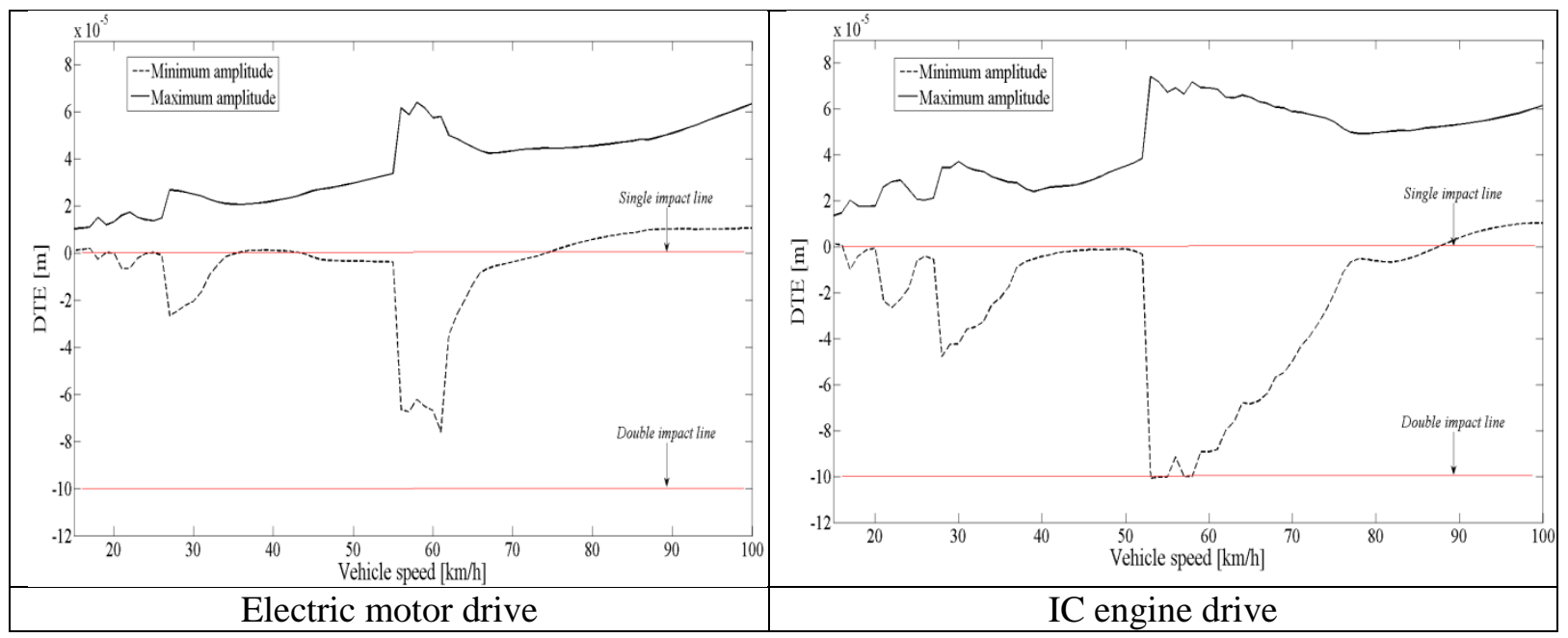

Figure 4: Sun-planet DTE frequency-amplitude plots for different driving power modes

Figure 5 shows the sun-planet DTE time history for different drive modes at $80 \mathrm{~km} / \mathrm{h}$. Higher peak-to-peak oscillations and teeth pair separations are noted with the IC engine power mode. An enlarged view of section $\mathrm{X}-\mathrm{X}$ is also presented, where the duration and qualitative characteristics of the meshing cycle are shown.

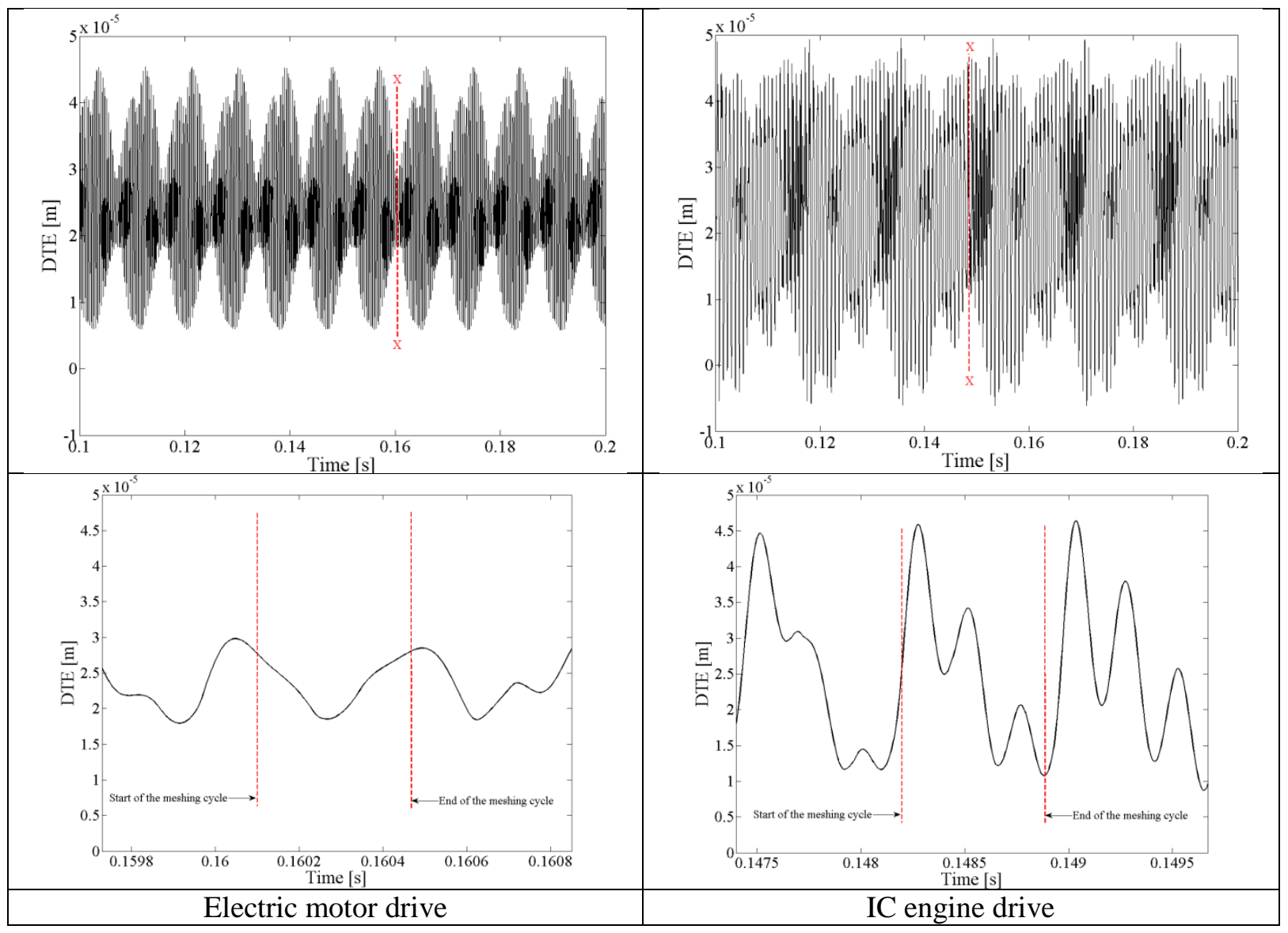

Figure 5: Time histories of the sun-planet DTE for different driving power modes at $80 \mathrm{~km} / \mathrm{h}$. 
For any root cause analysis during the design procedure, the effective frequencies observed in the DTE response are important. The FFT spectrum of the DTE for the IC engine mode is shown in figure 6. It reveals that the dominant contributions are at the meshing frequency $\left(f_{m}\right)$, the planet gear rotational frequency $\left(f_{p}\right)$, the ring gear rotational frequency $\left(f_{r}\right)$ and their modulations. A longer time history of the DTE is required in order to capture low frequency repetitive events, such as the periodic rotation of the planets and the ring gear. This also enables the effect of modulation with meshing frequency to be observed as shown in Figure 6 . In these analyses the resisting torque on the wheels is calculated using equation (28) and a sufficient supplied input torque is assumed to maintain steady state equilibrium. Therefore, any fluctuations of the engine output torque (engine order vibration [26]) are ignored for this analysis. If these effects were to be included, then further deterioration in the $\mathrm{NVH}$ performance would be expected.

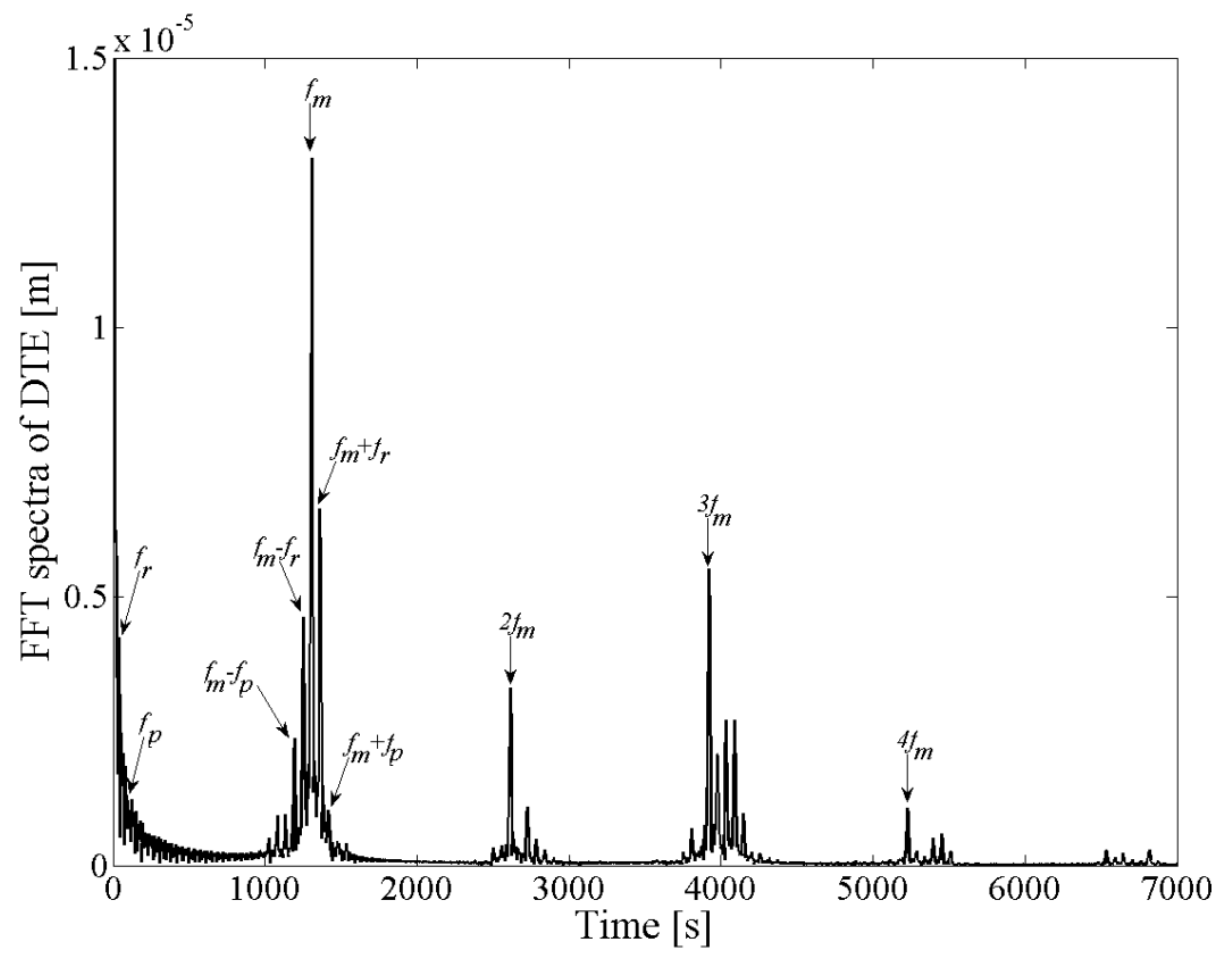

Figure 6: FFT spectrum of the sun-planet DTE for the IC engine driving mode at $80 \mathrm{~km} / \mathrm{h}$.

Figure 7 shows the lubricant film thickness variation for different power drive modes for the same time window of figure 5 (section $\mathrm{X}-\mathrm{X}$ ). A thicker film thickness in teeth pair meshing is noted for the EM drive mode. A sufficiently thick film thickness is noted to avoid the occurrence of mixed or boundary regimes of lubrication. In the IC engine mode, the predicted film thickness is in the range 1.2-2 $\mu \mathrm{m}$, which indicates a mixed regime of lubrication and, thus a larger number of asperity interactions would be expected compared with the case of EM mode (as it is also confirmed by the results presented in figure 8). 


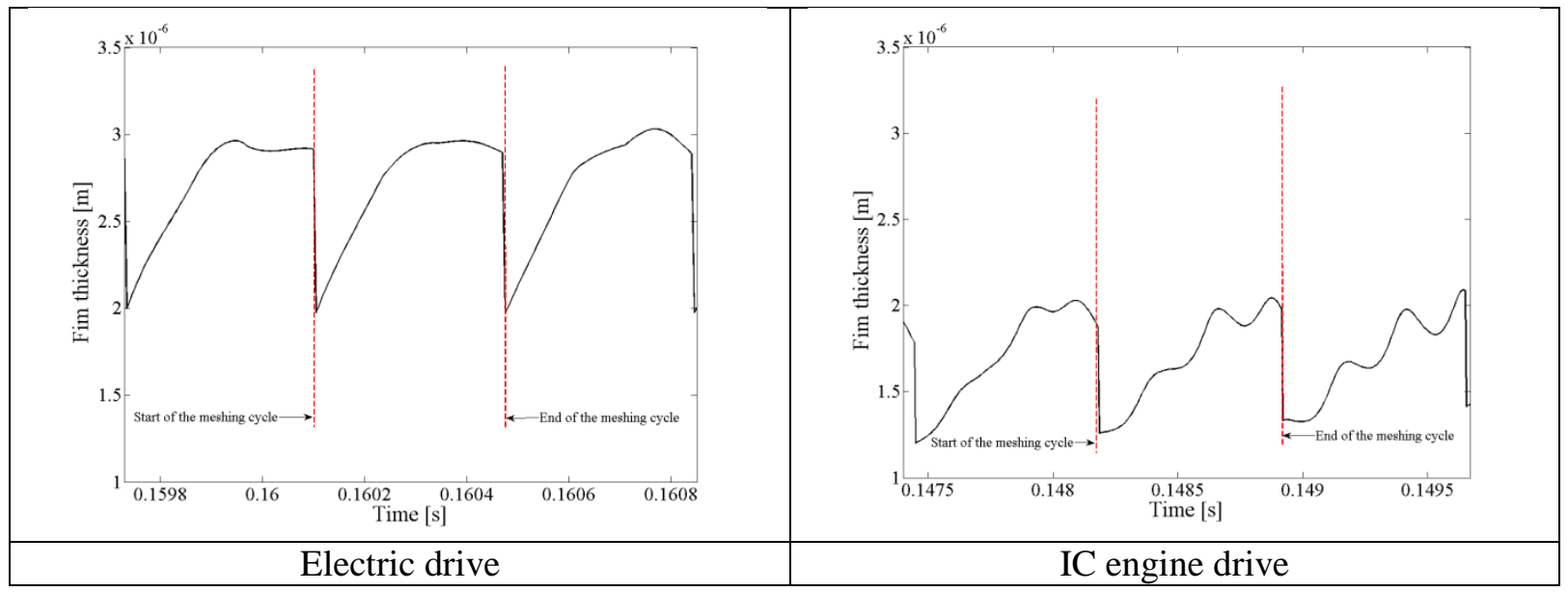

Figure 7: Lubricant film thickness time histories during meshing of the sun-planet teeth pairs for different driving power modes

The minimum lubricant film thickness values during the speed sweep simulation are presented in figure 8. Larger minimum film thickness values are noted for the EM power mode case.

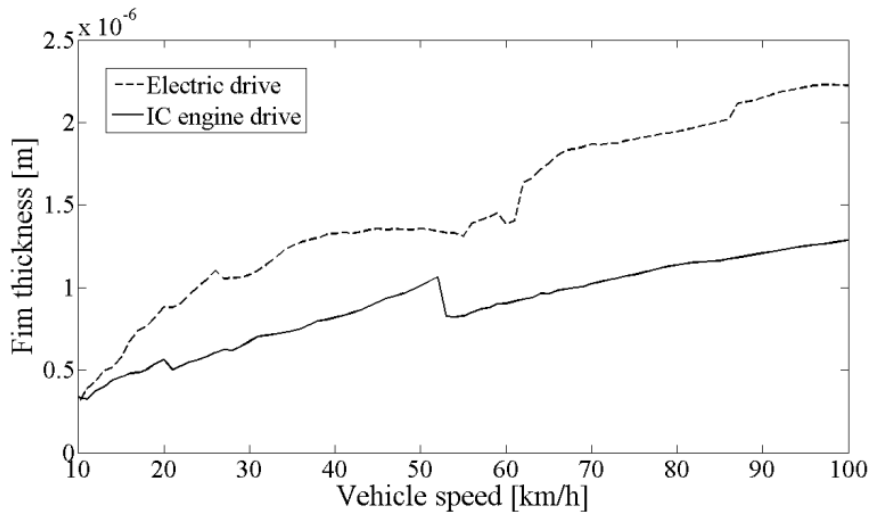

Figure 8: Sun-planet meshing minimum lubricant film thickness values during the speed sweep with different drive power modes

Finally, a key result of interest in the tribological analysis is the planetary gear set transmission efficiency (as the result of frictional losses) (figure 9). Comparing different driving modes, the IC engine generally shows better efficiency. This is despite the higher lubricant film thickness in the EM mode. The reason for this is the maintenance of a higher contacting sliding velocity of teeth pairs through meshing with the EM drive mode. The result is a higher viscous shear of the lubricant, resulting in increased viscous friction. At higher speeds, the inefficiency of both systems is comparable. 


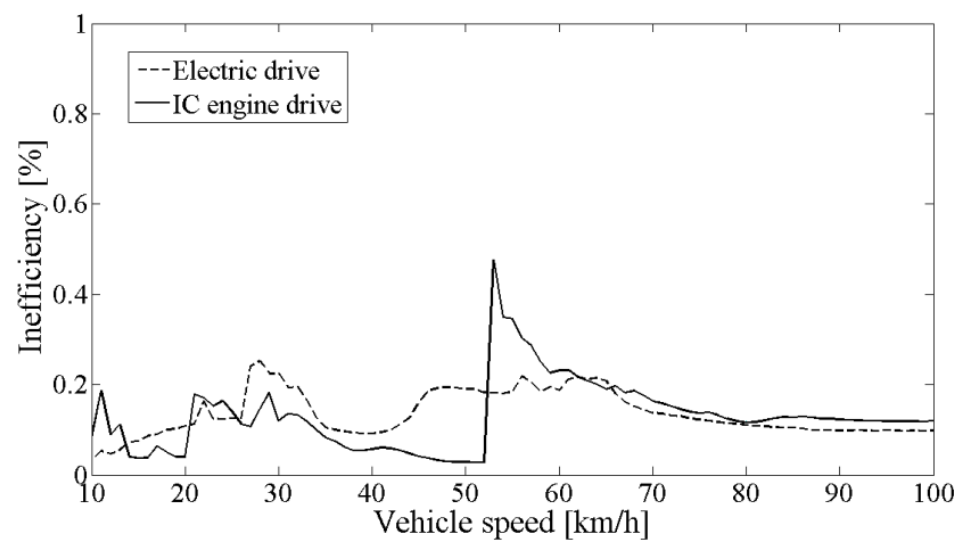

Figure 9: Total inefficiency of the planetary gear system due to gear meshing during the speed sweep simulations in different drive modes

\section{Conclusions:}

A tribo-dynamic analysis of a planetary gear set for HEV applications is presented. A 6 DOF torsional model has been developed taking into account the non-Newtonian, thermal and mixed elastohydrodynamics in order to predict the conjunctional lubricant film thickness, friction and gear set efficiency. For the considered configurations, the results show that in the EM drive mode, teeth pair separations occur for shorter regions during the speed sweep, when compared with the IC engine drive mode. The EM power mode also shows smaller peak-peak values for the DTE. Therefore, operations in the EM drive mode show better NVH performance. However, the latter reveals worse transmission efficiency at lower vehicle speeds. The conclusions arrived at in the current study apply to the investigated drive configuration. Therefore, they should be considered as specific to the problem described. There are many hybrid drive configurations though. Thus, generic conclusions would require studies of further alternatives. This constitutes a future aim of the current research. 


\section{References:}

[1] Won, S., Ashish, K., Sungwook, H. "6 speed automatic transmission vibration magnitude prediction and whine noise improvement through transmission system modelling”, SAE Technical paper 2011-01-153, 2011

[2] Kahraman, A. "Natural modes of planetary gear trains”, Journal of sound and Vibration, $1994,173,125-130$.

[3] Sun, T. and Hu, H.H. "Nonlinear dynamics of a planetary gear system with multiple clearances”, Mechanism and Machine Theory, 2003, 38, 1371-1390.

[4] Eisele, G., Wolff, K., and Alt., N. “Application of vehicle interior noise simulation for NVH analysis of a passenger car”, SAE Technical Paper 2005-01-2514, 2005

[5] Hwang, S.J., Stout, J.L. and Ling, C.C., "Modelling and analysis of powertrain torsional response”, SAE Technical Paper 980276, 1998

[6] Syed, F. U., Kuang, M. L. and Ying, H. “Active damping wheel-torque control system to reduce driveline oscillations in a power-split hybrid electric vehicle”, IEEE Trans. Veh. Technol., 2009, 58, 4769-4785.

[7] Kahraman, A., Vijayakar, S., "Effect of Internal Gear Flexibility on the Quasi-Static Behavior of a Planetary Gear Set”, Trans. ASME, Journal of Mechanical Design, 123, 2001, 408-415.

[8] Mohammadpour, M., Theodossiades, S. Rahnejat, H. "Transient mixed non-Newtonian thermo-elastohydrodynamics of vehicle differential hypoid gears with starved partial counterflow inlet boundary”, Proc. IMechE, Part J: Journal of Engineering Tribology, 228(10), 2014, 1158-1173, doi: 10.1177/1350650114537805

[9] Velex, P., and Cahouet, V., "Experimental and numerical investigations on the influence of tooth friction in spur and helical gear dynamics" Trans. ASME, J. Mech. Des., 2000, 122, 515-522.

[10] De la Cruz, M., Theodossiades, S. and Rahnejat, H. “An investigation of manual transmission drive rattle”, Proc. IMechE, Part K: J. Multi-body Dynamics, 224(2), 2010, 167181

[11]- Koronias, G., Theodossiades, S., Rahnejat, H. and Saunders, T. "Axle whine phenomenon in light trucks: a combined numerical and experimental investigation”, Proc. IMechE, Part D: J. Automobile Engineering, 225(7), 2011, 885-894 
[12] Dietl P., Wensing J. and Van Nijen G. C., "Rolling bearing damping for dynamic analysis of multi-body systems-experimental and theoretical results”, Proc. IMechE, Part K: Journal of Multi-body Dynamics, 214 (33), 2000, 33-43

[13] Mohammadpour, M., Theodossiades, S. and Rahnejat, H., "Multi-physics investigations on the dynamics of differential hypoid gears”, Trans. ASME, Journal of Vibration and Acoustics, 136(4), 2014, 041007.

[14] Mohammadpour, M., Theodossiades, S. and Rahnejat, H., “Tribodynamics of differential hypoid gears”, International Gear Conference, 2014, Lyon, France.

[15] Mohammadpour, M., Theodossiades, S., Rahnejat, H. and Kelly, P., "Transmission efficiency and noise, vibration and harshness refinement of differential hypoid gear pairs." Proc. IMechE, Part K: J. Multi-body Dynamics, 228(1), 2014, 19-33

[16] Inalpolat, M. and Kahraman, A. “Dynamic modelling of planetary gears of automatic transmissions”. Proc. IMechE, Part K: J. Multi-body Dynamics, 222(3), 2008, 229-242

[17] Ambarisha, V. K., Parker, R., "Suppression of Planet Mode Response in Planetary Gear Dynamics Through Mesh Phasing”, Trans. ASME, Journal of Vibration and Acoustics, 128, 2006, 133-142.

[18] Greenwood, J. A. and Tripp, J. H., “The contact of two nominally flat rough surfaces”, Proc. IMechE., J. Mech. Eng. Sci., 185, 1970-71, 625-633

[19] Gohar, R. and Rahnejat, H., "Fundamentals of Tribology”, Imperial College Press, London, 2008

[20] Johnson, K. L., and R. Cameron. "Fourth Paper: Shear Behaviour of Elastohydrodynamic Oil Films at High Rolling Contact Pressures." Proc. IMechE, J. Mech. Eng. Sci., 182 (1), 1967, 307-330

[21] Mohammadpour, M., Theodossiades, S., Rahnejat, H. and Saunders, T., "NonNewtonian mixed elastohydrodynamics of differential hypoid gears at high loads." Meccanica, 49(5), 2014, 1115-1138

[22] Evans, C. R. and Johnson, K. L. "Regimes of traction in elastohydrodynamic lubrication”, Proc. IMechE, J. Mech. Eng. Sci., 200 (5), 1986, pp. 313-324

[23] Dowson, D. and Higginson, G.,R., “Elasto-hydrodynamic lubrication”, Pergamon Press, Oxford, 1977.

[24] Zhang, J., Tang, X., Yu, H., \& Zou, L.. "Multi-body dynamics and noise analysis for the torsional vibration of a power-split hybrid driveline." Proceedings of the Institution of Mechanical Engineers, Part K: Journal of Multi-body Dynamics, 2014, DOI: 1464419314540152. 
[25] Karagiannis, I., Theodossiades, S. and Rahnejat, H., "On the dynamics of lubricated hypoid gears”. Mechanism and Machine Theory, 2012, 48, 94-120.

[26] Rahnejat, H., “Multi-body Dynamics: Vehicles, Machines and Mechanisms”, Professional Engineering Publishing, Bury St Edmunds, UK, 1998 